\title{
Image Enhancement through Contrast Improvement in ROI using Local PGI Model
}

\author{
I. Suneetha \\ Associate Professor \\ E.C.E Department \\ A.I.T.S, Tirupati A.P, India
}

\author{
T. Venkateswarlu, Ph.D \\ Professor of E.C.E S.V.U.C.E. \\ S.V.U,Tirupati, A.P, India
}

\begin{abstract}
Images are very powerful tools to provide information to the viewers in every field i.e. medical images for doctors, forensic images for police investigation, text images for readers etc. In the process of image acquisition, image clarity is affected by lighting, weather, distance, or equipment used for image capture. Sometimes quality of the image may be corrupted differently in various regions of an image. As contrast is one of the assessment factors for determining an image quality, it is necessary to develop a better and faster algorithm for contrast improvement in regions of interest. This paper proposes a method for image enhancement through contrast improvement in regions of interest using a Local Parameterized Gradient Intercept (LPGI) Model in spatial domain. The proposed method provides good results subjectively as well as objectively for both gray scale and true color images. The proposed method is useful for interactive image processing applications as it has a family of possible transformations for various enhancement levels in different regions of interest.
\end{abstract}

\section{Keywords}

Global Histogram Equalization (GHE), Local Histogram Equalization (LHE), Global Adaptive Equalization (GAE), Local Adaptive Equalization (LAE), and Global Parameterized Gradient Intercept (GPGI), Local Parameterized Gradient Intercept (LPGI), Region Of Interest (ROI).

\section{INTRODUCTION}

Image enhancement improves digital image quality without knowing the source of degradation and provides visually acceptable images for human viewers and/or automated image processing techniques. We reviewed enhancement techniques for gray scale images in spatial domain [1] and implemented them using MATLAB. These techniques have been successfully extended to true color images [2]. Image enhancement process gives better visual quality either by increasing the contrast or suppressing the noise. Image enhancement can be done through contrast improvement using a linear PGI model [3]. Image enhancement through noise suppression can be done using a nonlinear PAR model [4]. Image enhancement through contrast improvement and noise suppression can be done using a Parameterized Hybrid model [5]. These three global models: linear, nonlinear, and hybrid work well when entire image is corrupted uniformly. They fail to enhance when various regions of an image corrupted differently. This paper proposes a method for image enhancement through contrast improvement in ROI using a Local PGI model in spatial domain.

\section{PROPOSED METHOD}

Let $f(x, y)$ be a digital image of size $\mathrm{MxN}$ and $g(x, y)$ be its enhanced image along with respective pixel values $r$ and $s$. The transformation for proposed model for $\mathrm{i}=1,2,3, \ldots . \mathrm{n}$ is given by

$$
\begin{aligned}
& g_{i}(x, y)=G_{i} * f_{i}(x, y)+I_{i} \\
& \Rightarrow s_{i}=G_{i}^{*} r_{i}+I_{i}
\end{aligned}
$$

where $n$ is the number of regions of interest, $G_{i}$ and $I_{i}$ are the Gradient and Interception of $i^{\text {th }}$ region of interest. $G_{i}$ and $I_{i}$ values can be zero, positive, or negative. When $G_{i}$ and/or $I_{i}$ values are varied for improving the image contrast, above transformation becomes simple linear or nonlinear but not exponential or logarithmic as in traditional point processing methods [6][7]. Proposed method needs simple operations and does not require PDF calculations for finding histogram of an image as in GHE and GAE methods [8].

The proposed method is given the name 'Local Parameterized Gradient Intercept (LPGI) model', as a family of possible transformations can be obtained for achieving effective image enhancement for region of interest.

\section{LPGI ALGORITHM}

The following are the steps involved in image enhancement through contrast improvement in ROI using LPGI algorithm for gray scale and true color images.

\section{Gray scale image:}

1. Read input image $\mathrm{i}(\mathrm{x}, \mathrm{y})$

2. Corrupt the image $i(x, y)$ to get $f(x, y)$

3. Divide $f(x, y)$ into two sub images based on ROI: $f_{1}(x, y)$ and $f_{2}(x, y)$

4. For $\mathrm{f}_{1}(\mathrm{x}, \mathrm{y})$,select appropriate $\mathrm{G}_{1}$ and $\mathrm{I}_{1}$.

5. Multiply $f_{1}(x, y)$ with $G_{1}$ and add with $I_{1}$ to get $\mathrm{g}_{1}(\mathrm{x}, \mathrm{y})$.

6. If $\mathrm{g}_{1}(\mathrm{x}, \mathrm{y})$ is not good in contrast change $\mathrm{G}_{1}$ and/or $\mathrm{I}_{1}$, then go to step5

7. For $\mathrm{f}_{2}(\mathrm{x}, \mathrm{y})$,select appropriate $\mathrm{G}_{2}$ and $\mathrm{I}_{2}$.

8. Multiply $f_{2}(x, y)$ with $G_{2}$ and then add $I_{2}$ to get $\mathrm{g}_{2}(\mathrm{x}, \mathrm{y})$.

9. If $\mathrm{g}_{2}(\mathrm{x}, \mathrm{y})$ is not good in contrast change $\mathrm{G}_{2}$ and/or $\mathrm{I}_{2}$, then go to step 8 .

10. Get enhanced output image $g(x, y)$ from $\mathrm{g}_{1}(\mathrm{x}, \mathrm{y})$ and $\mathrm{g}_{2}(\mathrm{x}, \mathrm{y})$.

True Color image:

1. Read input image $i(x, y)$.

2. Corrupt the image $i(x, y)$ to get $f(x, y)$

3. Divide $f(x, y)$ into two sub images based on ROI: $f_{1}(x, y)$ and $f_{2}(x, y)$ 
4. For $\mathrm{f}_{1}(\mathrm{x}, \mathrm{y})$, select values of $\mathrm{G}_{1}$ and $\mathrm{I}_{1}$.

5. Extract $r, g, b$ components from $\mathrm{f}_{1}(\mathrm{x}, \mathrm{y})$

6. Multiply $r_{1}(x, y), g_{1}(x, y)$, and $b_{1}(x, y)$, with $G_{1}$ and add with $I_{1}$ to get $h_{1}(x, y)$.

7. If $h_{1}(x, y)$ is not good in contrast change $\mathrm{G}_{1}$ and/or $\mathrm{I}_{1}$, then go to step 6 .

8. For $f_{2}(x, y)$, select values of $G_{2}$ and $I_{2}$.

9. Extract $\mathrm{r}, \mathrm{g}, \mathrm{b}$ components from $\mathrm{f}_{2}(\mathrm{x}, \mathrm{y})$

10. Multiply $r_{2}(x, y), g_{2}(x, y)$, and $b_{2}(x, y)$, with $G_{2}$ and add with $\mathrm{I}_{2}$ to get $\mathrm{h}_{2}(\mathrm{x}, \mathrm{y})$.

11. If $\mathrm{h}_{2}(\mathrm{x}, \mathrm{y})$ is not good in contrast change $\mathrm{G}_{2}$ and/or $\mathrm{I}_{2}$, then go to step 10 .

12. Get enhanced output image $h(x, y)$ from $h_{1}(x, y)$ and $h_{2}(x, y)$.

\section{RESULTS}

The LPGI model performance can be compared to that of GHE, LHE, GAE, LAE, and GPGI methods. Consider two gray scale images of file TIF type : Lena $(512 \times 512)$ and Man(256x256) and then two true color images of file JPG type: Pepper(384x512) and Thajl(256x256). These images are shown in figures Fig. (1-4) have been corrupted differently in two regions. Corrupted images are then enhanced by Global methods: GHE, GAE, and GPGI. Let the corrupted image can be segmented into two regions $\mathrm{ROI}_{1}$ and $\mathrm{ROI}_{2}$. They are either left half and right half or top half and bottom half. Segmented images are then enhanced by local methods: LHE, LAE, and LPGI. Contrast improvement can be judged by visual inspection of the resultant images along with their histograms and also by evaluating the mean square error for each method [9-15].

$M S E=\frac{1}{M N} \sum_{i=1}^{M} \sum_{j=1}^{N}[f(i, j)-g(i, j)]^{2}$

Subjective results for gray scale images are shown in figures (Fig. 5-20) and for true color images in figures (Fig. 21-36). Objective results for gray scale images are given in table 1 and for true color images in tables 2 .

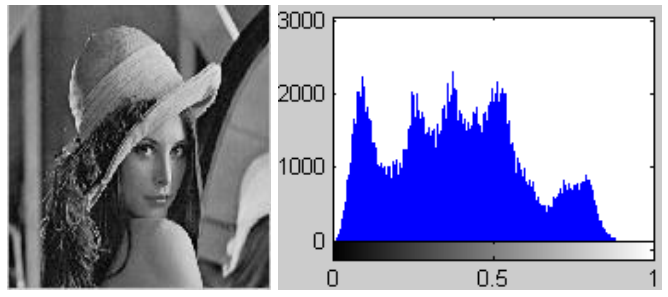

Fig 1: Lena image and its histogram

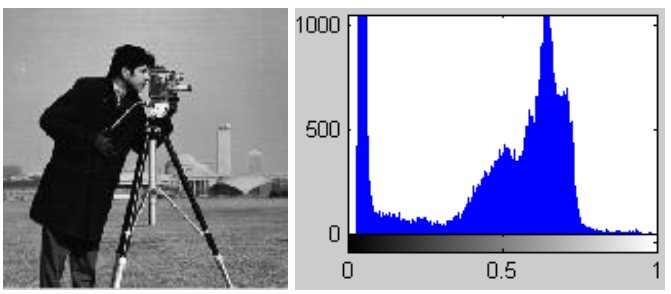

Fig 2: Man image and its histogram
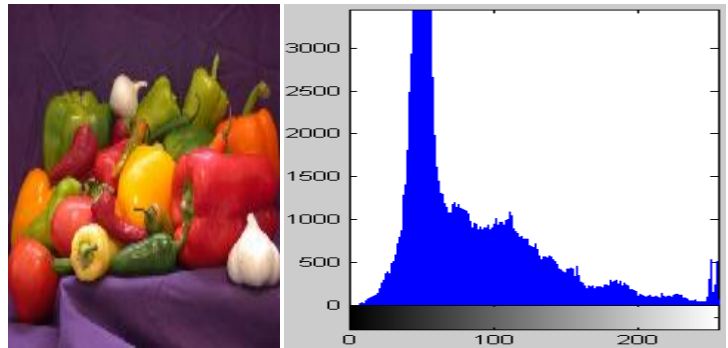

Fig 3: Pepper image and its histogram
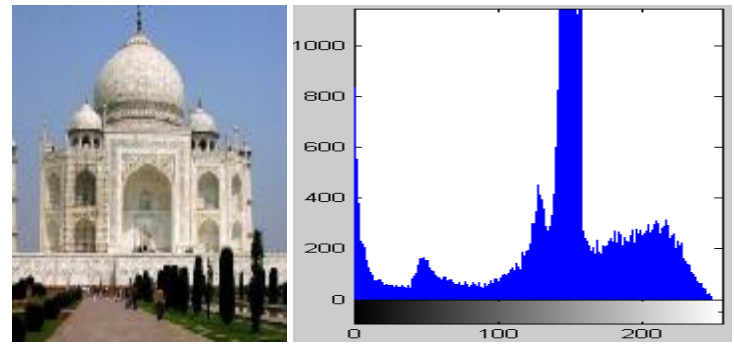

Fig 4: Thaj image and its histogram

Table 1. MSE for gray scale images

\begin{tabular}{|c|c|c|}
\hline Image & Lena & Man \\
\hline Original & 1.1686 & 1.0378 \\
\hline G H E & 0.1187 & 0.1620 \\
\hline L H E & 0.1188 & 0.0999 \\
\hline G A E & 0.1245 & 0.1741 \\
\hline L A E & 0.1257 & 0.1753 \\
\hline GPGI1 & 0.0600 & 23.526 \\
\hline GPGI2 & 8.0496 & 0.1512 \\
\hline L P G I & 0.0001 & 0.0001 \\
\hline
\end{tabular}

Table 2. MSE for true color images

\begin{tabular}{|c|c|c|c|}
\hline \multirow{2}{*}{ Image } & \multicolumn{3}{|c|}{ Pepper } \\
\cline { 2 - 4 } & $\mathbf{M S E}_{\mathbf{R}}$ & $\mathbf{M S E}_{\mathbf{G}}$ & $\mathbf{M S E}_{\mathbf{B}}$ \\
\hline Original & 0.0938 & 0.0987 & 0.0849 \\
\hline G H E & 0.0680 & 0.0794 & 0.0737 \\
\hline L H E & 0.0577 & 0.0821 & 0.0787 \\
\hline G A E & 0.0787 & 0.0907 & 0.0802 \\
\hline L A E & 0.0799 & 0.0912 & 0.0803 \\
\hline GPGI & 0.0570 & 0.0993 & 0.0953 \\
\hline GPGI & 0.0471 & 0.0191 & 0.0127 \\
\hline L P G I & $1.94 \mathrm{e}-5$ & $2.04 \mathrm{e}-5$ & $2.03 \mathrm{e}-5$ \\
\hline \multirow{3}{*}{ Image } & \multicolumn{3}{|c|}{ Thaj } \\
\cline { 2 - 4 } & $\mathbf{M S E}_{\mathbf{R}}$ & $\mathbf{M S E}_{\mathbf{G}}$ & $\mathbf{M S E}_{\mathbf{B}}$ \\
\hline Original & 0.0730 & 0.0839 & 0.1019 \\
\hline G H E & 0.0464 & 0.0561 & 0.0697 \\
\hline L H E & 0.0341 & 0.0402 & 0.0443 \\
\hline G A E & 0.0631 & 0.0737 & 0.0898 \\
\hline L A E & 0.0633 & 0.0737 & 0.0902 \\
\hline GPGI & 0.0422 & 0.0455 & 0.0524 \\
\hline GPGI2 & 0.0536 & 0.0536 & 0.0868 \\
\hline L P G I & $2.04 \mathrm{e}-5$ & $2.05 \mathrm{e}-5$ & $2.05 \mathrm{e}-5$ \\
\hline
\end{tabular}



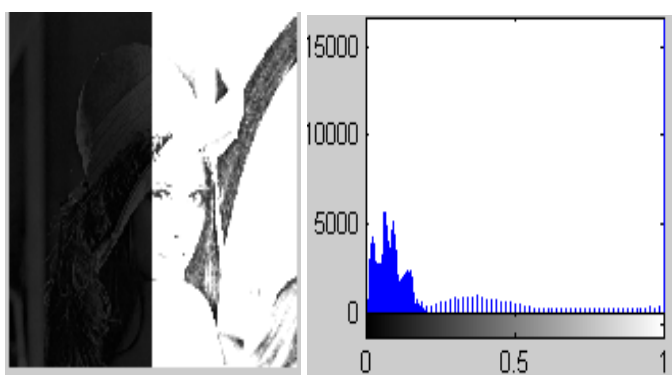

Fig 5: Corrupted image and its histogram
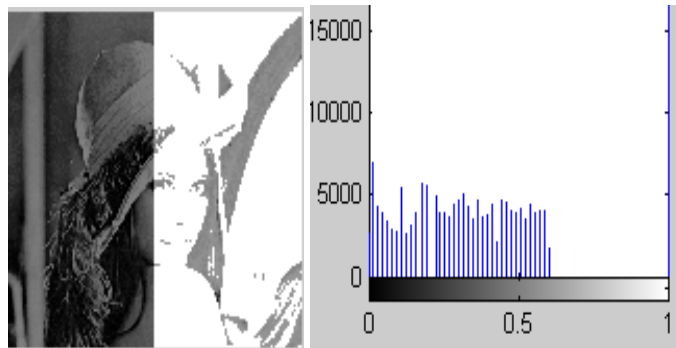

Fig 6: GHE image and its histogram

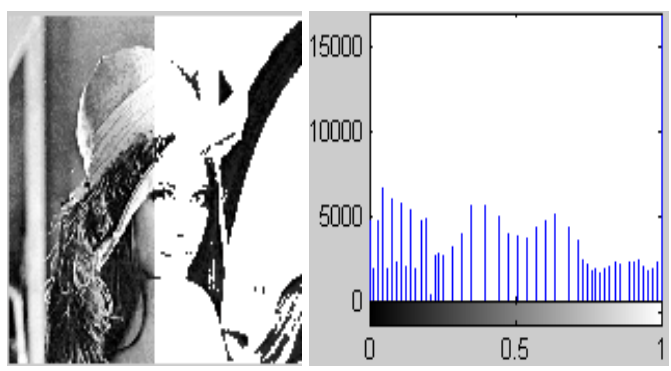

Fig 7: LHE image and its histogram
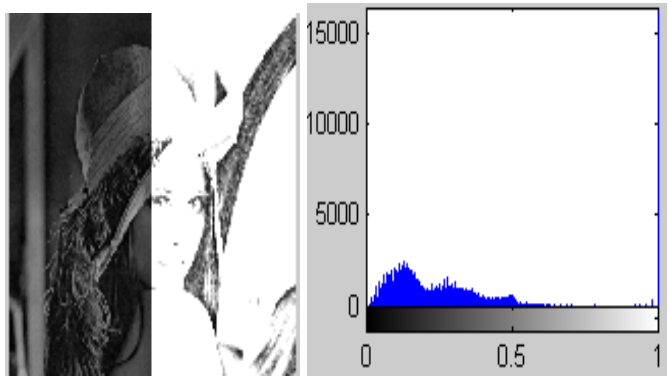

Fig 8: GAE image and its histogram

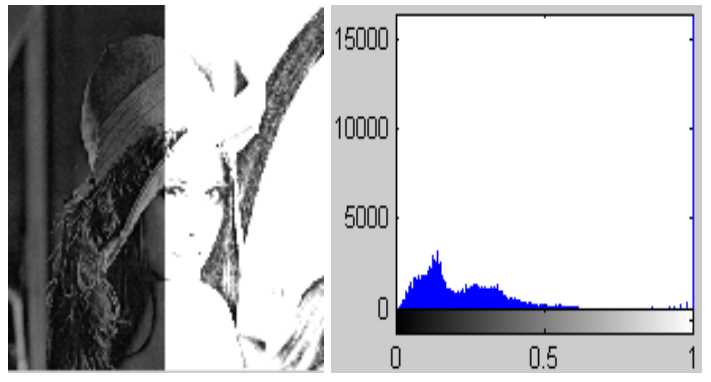

Fig 9: LAE image and its histogram

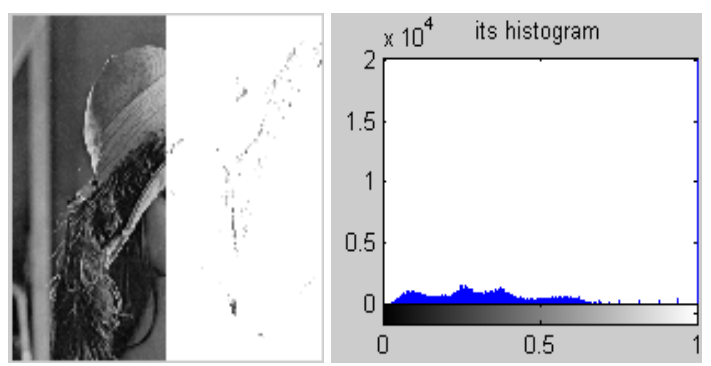

Fig 10: GPGI1 image and its histogram

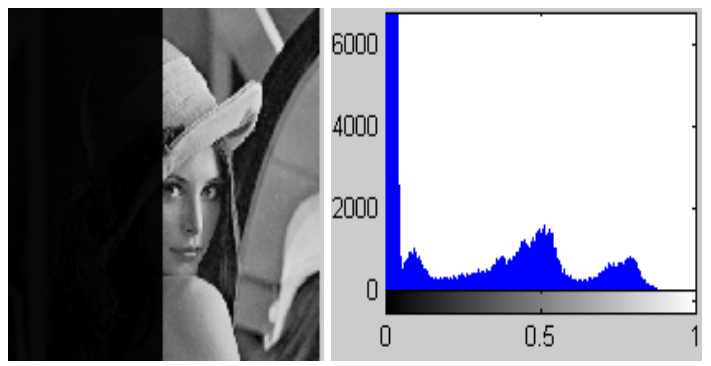

Fig 11: GPGI2 image and its histogram
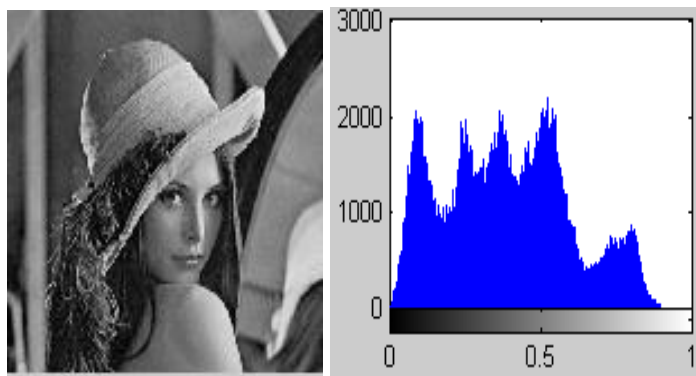

Fig 12: LPGI image and its histogram 


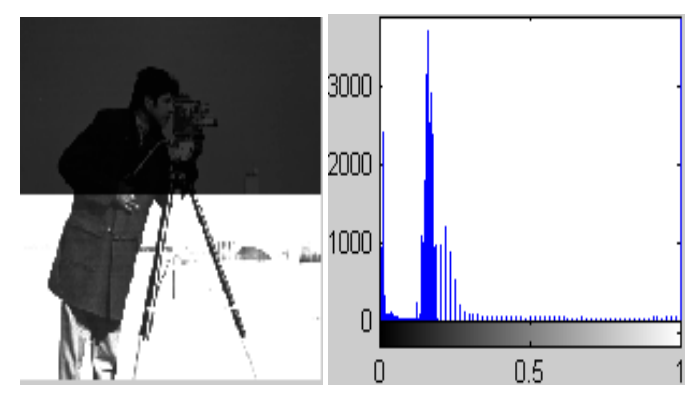

Fig 13: Corrupted image and its histogram

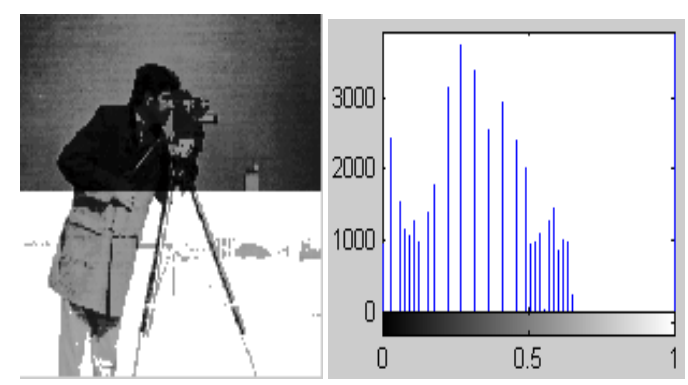

Fig 14: GHE image and its histogram

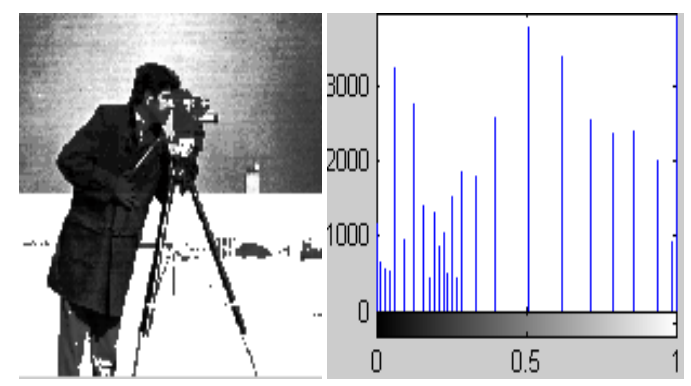

Fig 15: LHE image and its histogram

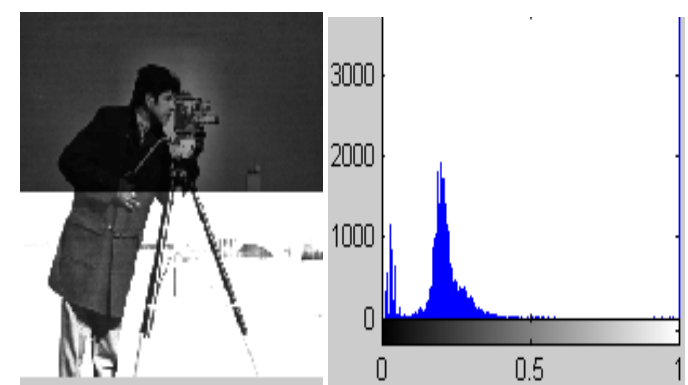

Fig 16: GAE image and its histogram

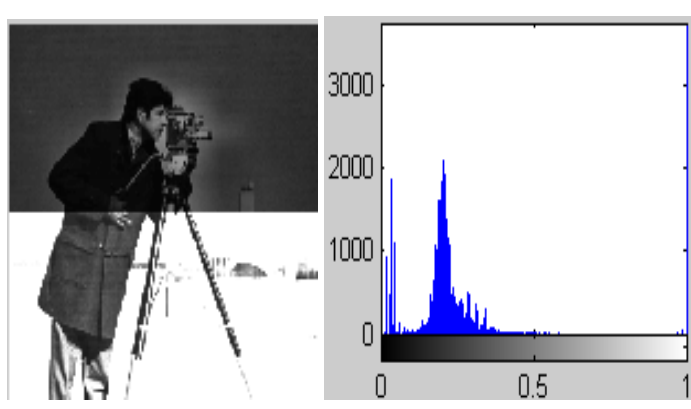

Fig 17: LAE image and its histogram

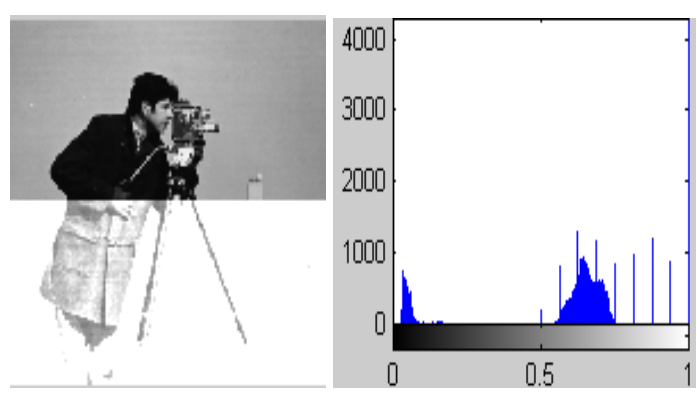

Fig 18: GPGI1 image and its histogram
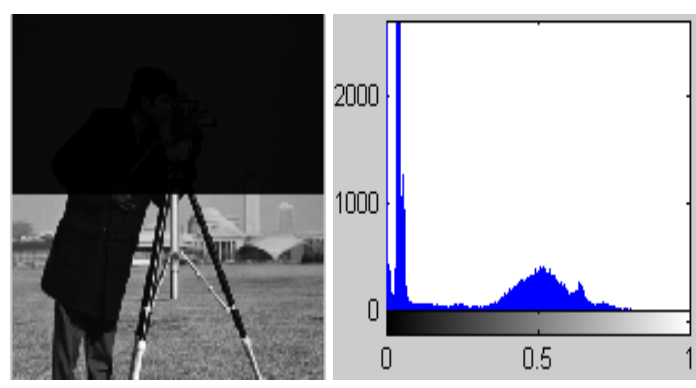

Fig 19: GPGI2 image and its histogram
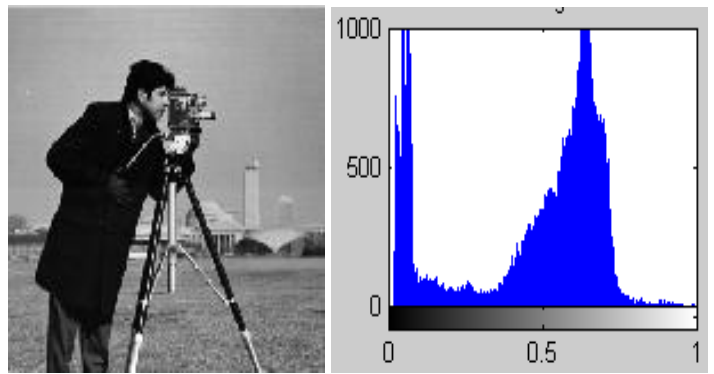

Fig 20: LPGI image and its histogram 

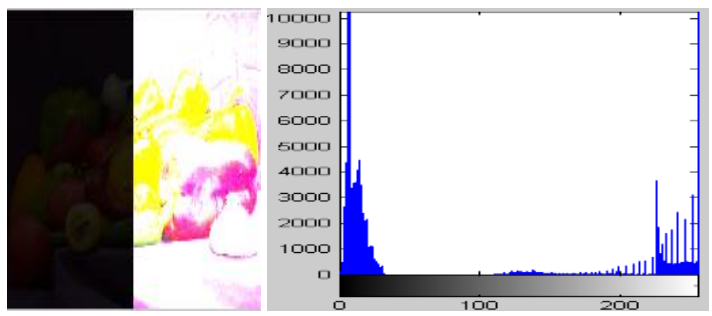

Fig 21: Corrupted image and its histogram

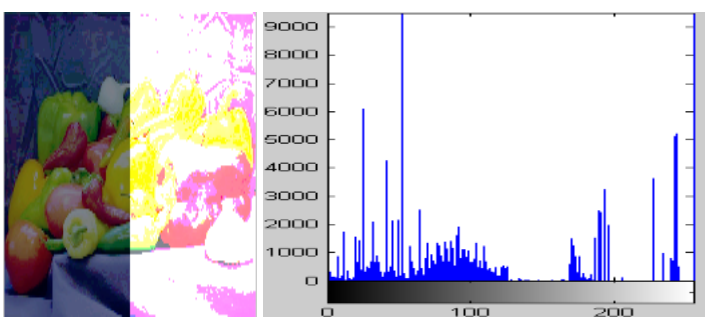

Fig 22: GHE image and its histogram

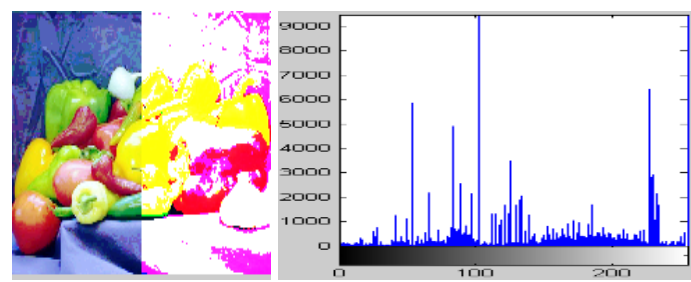

Fig 23: LHE image and its histogram
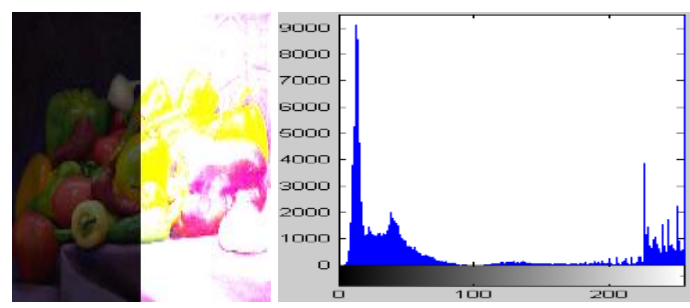

Fig 24: GAE image and its histogram
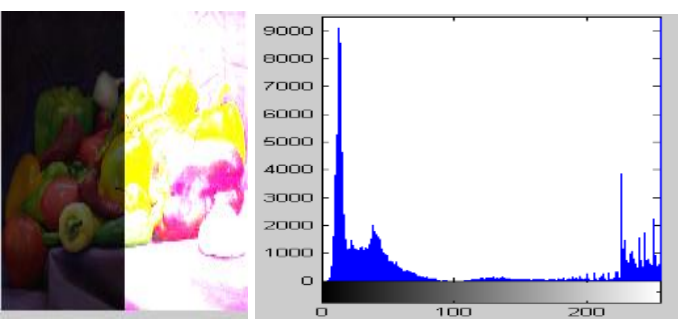

Fig 25: LAE image and its histogram
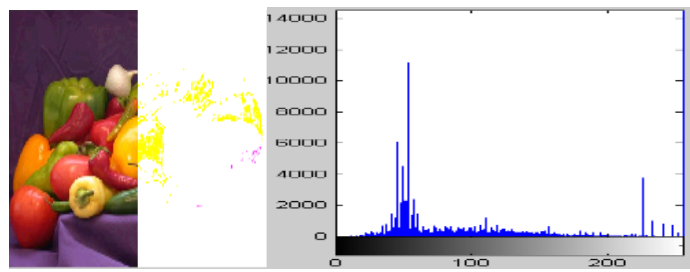

Fig 26: GPGI1 image and its histogram

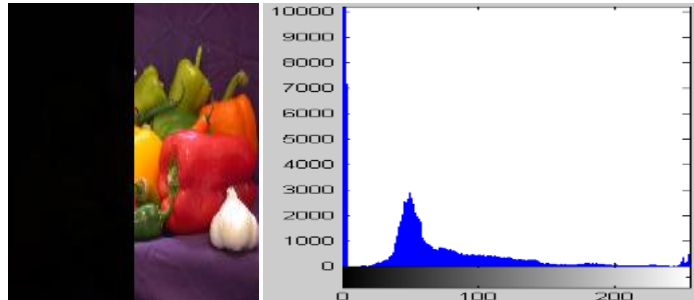

Fig 27: GPGI2 image and its histogram
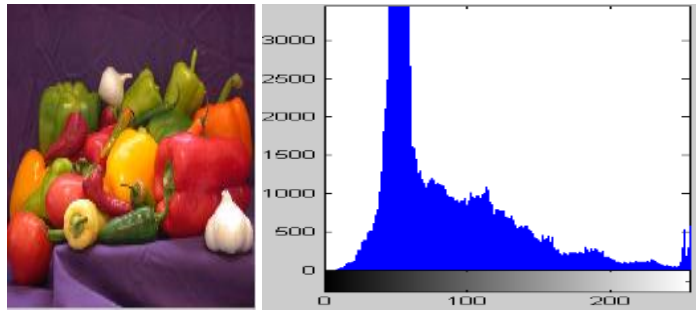

Fig 28: LPGI image and its histogram

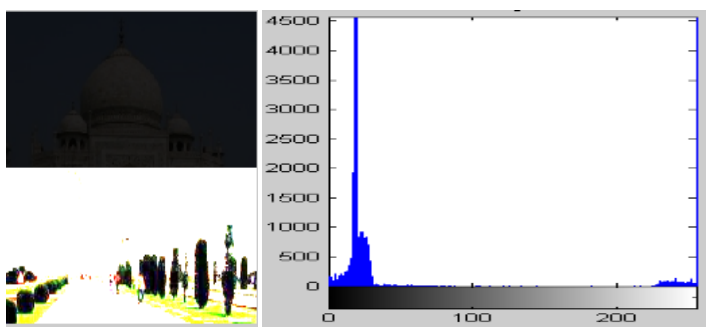

Fig 29: Corrupted image and its histogram

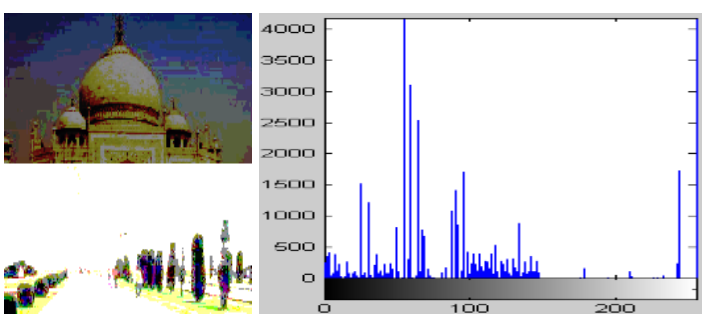

Fig 30: GHE image and its histogram

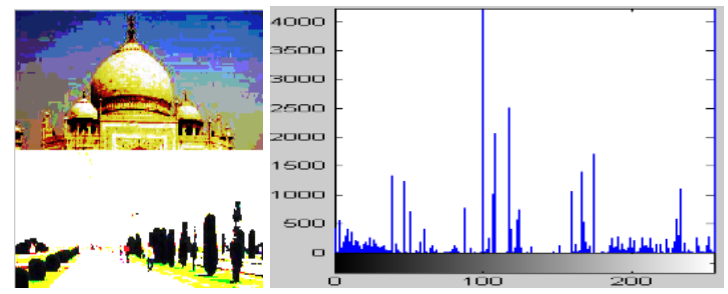

Fig 31: LHE image and its histogram

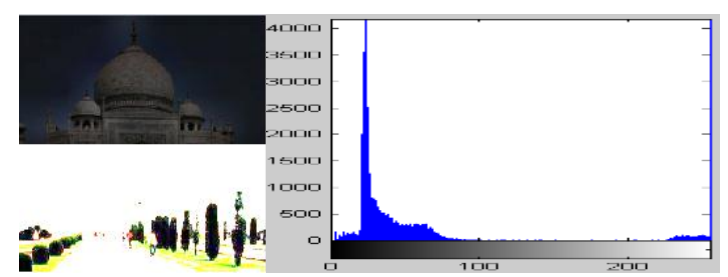

Fig. 32: GAE image and its histogram 


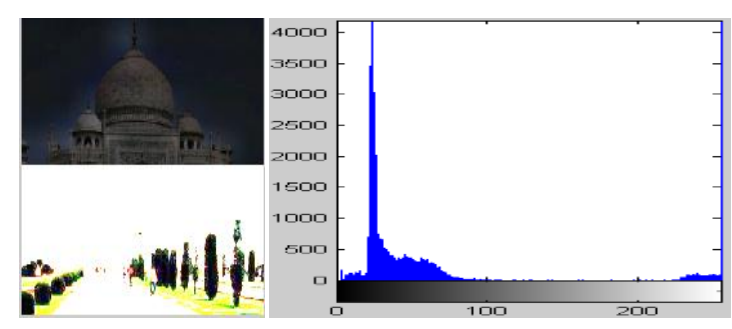

Fig 33: LAE image and its histogram

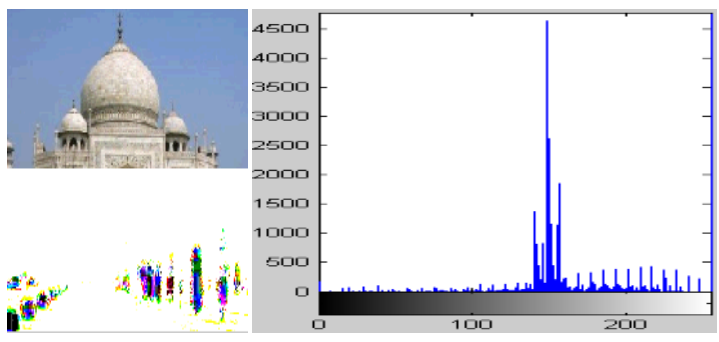

Fig 34: GPGI1 image and its histogram

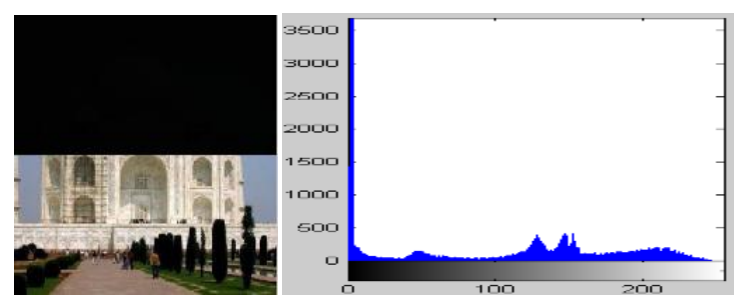

Fig 35: GPGI2 image and its histogram

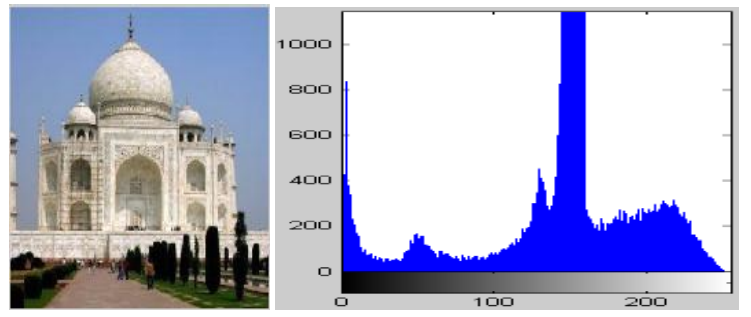

Fig 36: LPGI image and its histogram

\section{DISCUSSIONS}

Visual inspection of subjective results indicates that, GHE, LHE, GAE, LAE methods fail to enhance images that are corrupted differently in two regions. GPGI method enhances only one region where as proposed LPGI model works very well by enhancing both regions of gray scale and true color images. Visual inspection of objective results shows that LPGI method has smaller mean square error for the gray scale images and also for the R, G, and B components of true color images. Simulation results for an image are restricted to two regions only. Proposed algorithm can be extended to any number of regions. The proposed model can be applied to enhance the images that are segmented in rectangular or square shape only. This limitation can be overcome by slight change in LPGI algorithm for selecting spatial coordinates to enhance the any shape of ROI.

\section{CONCLUSIONS}

Image enhancement through contrast improvement in ROI using LPGI has been successfully implemented for both gray scale and true color images in spatial domain. LPGI model works well for a gray scale images and results are much more pronounced for true color image by preserving maximum color details. Choice of $\mathrm{G}$ and I depend on the type of image. LPGI method can be used as a tool for Photo editing software like Photoshop or any existing image processing software by providing two sliding bars for selecting spatial coordinates $\mathrm{x}$ and $y$ of ROI and then two more sliding bars for G and I for image enhancement. Sometimes an image can be corrupted by different amounts of noise intensities in its various regions. The future scope will be the development of local parameterized model for achieving image enhancement through noise suppression in ROI from noisy images.

\section{REFERENCES}

[1] Ms. I.Suneetha and Dr.T.Venkateswarlu, "Enhancement Techniques for Gray scale Images in Spatial Domain", International Journal of Emerging Technology and Advanced Engineering, website: www.ijetae.com(ISSN 2250-2459) Volume 2, Issue 4, April 2012, pp.13-20.

[2] Ms. I.Suneetha and Dr.T.Venkateswarlu, "Enhancement Techniques for True Color Images in Spatial Domain", International Journal of Computer Science \& Technology (IJCST), Website: www.ijcst.com(ISSN Online 0976-8491, ISSN Print 2229-4333) Volume 3, Issue 2, Version 5, April to June 2012, PP. 814-820.

[3] Ms. I.Suneetha and Dr.T.Venkateswarlu, "Image Enhancement Through Noise Suppression Using Nonlinear Parameterized Adaptive Recursive Model", International Journal of Engineering Research and Applications (IJERA), Website: www.ijera.com (ISSN 2248-9622), Volume 2, Issue 4,July-August 2012, pp. 1129-1136.

[4] Ms. I.Suneetha and Dr.T.Venkateswarlu, "Image Enhancement Through Contrast Improvement Using Linear Parameterized Gradient Intercept Model", ARPN Journal of Engineering and Applied Sciences (ARPN-JEAS), Website:www.arpnjournals.com (ISSN 18196608), Volume 7, No. 8, August 2012.

[5] Ms. I.Suneetha and Dr.T.Venkateswarlu, "Spatial Domain Image Enhancement Using Parameterized Hybrid Model", International Journal of Electronics and Communication Engineering (IJECET), Website:www.iaeme.com (ISSN Print 0976-6464, ISSN Online 0976-6472), Volume 3, Issue 2, July-September (2012), pp. 209-216.

[6] R C Gonzalez, R. E. Woods, Digital Image Processing, $3^{\text {rd }}$ Edition, Prentice Hall, 2008.

[7] Kh. Manglem Singh, Romen Singh, Rupachandra Singh, and O.Imocha Singh", Image Enhancement by Adapted Power Law Transformation", BUJICT, September 2010.

[8] J. Y. im, L. S. Kim, S. H Hwang, "An advanced Contrast Enhancement Using Partially Overlapped Sub-Block Histogram Equalization", IEEE Transactions on Circuits and Systems for Videc 
Technology, Vol. 11, No. 4, pp.475-484,2001.

[9] Abdel-Ouahab BOUDRAA, EI-Hadji Samba DIOP, "Image Contrast Enhancement Based on 2D Teager-Kraiser Operator”, ICIP,IEEE 978-1-4244$1764,2008$.

[10] J Rafael C Gonzalez, Richard E. Woods, and Steven L. Eddins, Digital Image Processing Using MATLAB ${ }^{\circledR}$ (Second Edition, Gates mark Publishing, 2009).

[11] Prof. A. Senthilrajan, Dr. E. Ramaraj, "High Density Impulse Noise Removal in Color Images Using Region of Interest Median Controlled Adaptive Recursive Weighted Median Filter", Proceedings of the International MultiConference of Engineers and Computer Scientists (IMECS), Vol. II, March 17-19, 2010, Hong Kong.
[12] J.S.Lee,'Digital image enhancement and noise filtering by use of local statistics",IEEE Trans. On Pattern Analysis and Machine Intelligence, PAMI$2: 165,1980$.

[13] Color image processing: pseudo color processing Spring 2008 ELEN 4304/5365 DIP 1by Gleb V. Tcheslavski

[14] J.Astola, P.Kuosmaneen, "Fundamentals of Nonlinear Digital Filtering", Boca Raton, FL: CRC, 1997.

[15] Raman Maini and Himanshu Aggarwal, "A Comprehensive Review of Image Enhancement Techniques", Journal of Computing (ISSN 21519617), Volume 2, Issue 3, March 2010, pp. 8-13. 